\title{
Transforming an Intermittent Into 24x7 Water Supply System in Sector No. 4 \& 6 of Pcmc Pune
}

\author{
Ms. P.M.Pathak ${ }^{1}$, Mr. S.D. Jaybhaye ${ }^{2}$,Mr. P.H. Gehlot ${ }^{2}$, Ms.V.V.Patil ${ }^{2}$, Ms. \\ A.P.Jaybhay ${ }^{2}$, Ms.K.Kumari ${ }^{2}$ \\ Asst. Prof. Department of Civil Engineering, SAOE, Kondhwa, Pune-48 \\ Student, Department of Civil Engineering, SAOE, Kondhwa, Pune-48
}

\begin{abstract}
Water is very important for life,so it must be make sure that everyone is getting it in adequate amount.water supply is also very important for achieving good health for all. The ambition of Pimpri Chinchwad Municipal Corporation (PCMC), Pune (Sector No. 21) is to supply safe and potable water for $24 x 7$ hours to the people. This can be achievedby framing the legislation on regulation of drinking water through a scheme which is named as $24 x 7$ water supply scheme. In continuous water supply, PCMC (Sector No. 21) taking the efforts to provide quality and its continuous supply to the consumer. Hence before provision of continuous water supply, we have considered 'leakages' in the distributaries as it is the most responsible factor for water contamination. Wastage of water is also because of leakage which occurs in water mains therefore it's very important to detect leakage. For detecting leakage helium gas was used. This technique is easy to operate as well as safeand also give have accurate results to find leakages in water mains, therefore it is used.
\end{abstract}

Keywords: Water Leak Detection, Pipe Lines, Helium Gas Leak Detector, Successful Implementation.

\section{"Jal Hai to Jeevan Hai"}

\section{Introduction}

It's very true, life of all living creature is depend upon water. Earth is the only knownplanet in this universe where life is possible only because of the availability of water and oxygen. So it's very essential that everyone get adequate amount of water.So that they can use it according to their need. Due to increase in population the demand of water also increases. As population has growing day by day this has made rise in industrial sector. Three fourth of the earth is covered by water from which $97 \%$ water is oceanwater means salt water and completely unfit for our consumption. Left percentage (about $2.7 \%$ ) is fresh drinking water however around $70 \%$ of this is available as ice sheet and glaciers in Antarctica. so, we only have 1\% of fresh water which is fit for human use.According to the World Water Development Report, 1.1 billion people worldwide do not have access to safe drinking water. This is expected to touch 2 billion by 2050.1.6 million die every year due to diseases related to poor sanitation and polluted water supply. So, it is necessary to provide potable water to the civilians of society to ensure their health. The source water which are polluting the underground water are land runoff, drainage,seepage, sewage, etc. so it's must me make sure that the water which is supplied to the consumer are free from harmfulchemicals. Water is collected from source i.e. reservoir and it conveyed to water treatment plant through the pipe lines and it treated over there and make the water drinkable and then it supplied to ESR (Elevated

Service Reservoir). After this it is supplied to the consumer as per requirement. There are two types of water supply from

which water is supplied to the consumers one is intermittent water supply and the other one is continuous water supply.

Basically in India Intermittent Water Supply System is used to supply drinking water to people by the Local bodies. In this system water is supplied to users for particular period of time in a day i.e. in the morning or evening or as per the schedule time. Water is supplied to the users usually at the peak hours of the water usage i.e. morning 6 am to 9 am and evening $5 \mathrm{pm}$ to $8 \mathrm{pm}$. As water comes for particular period of time therefore user have to store water so that they can use rest of the day and at the very next day consumer throw the water which they have collected so that they can collect the fresh water. This has make increase in $\%$ of wastage of water. There are many disadvantage of intermittent water supply like contamination of water due to leakages in pipe, irregularity in water supply etc.

Due to this continuous water supply system is used to overcome these problems.It's a pressurized water supply system, supplying water round the clock for all seven days a week and all weeks of year. In this user don't have to collect water as water is available for $24 * 7$. There are many advantages like $24 * 7$ system reduces contamination level as the pipes are under positive pressure and entry of contaminants into the pipes is restricted. Due to steady pressure in the pipe increase the life of pipe distribution network. No fatigue for pipes. 
A better demand management is possible due to elaborate metering and effective leakage control. It is also easy $\&$ just to calculate water charges based on consumed volume. Reduction in consumption due to change in habit from storing of water to non-storing, also it generate excellent customer satisfaction. People can manage their time effectively; they can allot more time for rewarding activitiesDue to fully metered system easy to carry out water.

\section{Literature Survey}

Dr. Sanjay and V. Dahasahasra has studied on the water crisis, millennium development goals, access to safe water - Indian scenario. According to the World Water Development Report, 1.1 billion people worldwide do not have access to safe drinking water. This figure is expected to touch 2 billion by 2050.1 .6 million die every year due to diseases related to poor sanitation and polluted water supply and 160 million are infected with Schistosomiasis while 133 million suffer from high- intensity intestinal helminth infections.

Rutva N. Gohil has analyzed the critical responsibilityof declining availability of water supplies is one of the most important environmental issues facing various countries at the present time. Climate change, affluence and population growth have resulted in vast requirements of water for use in domestic, industrial and agricultural settings. Water has remained the most severe issue confronting the Urban Local Bodies (ULB), whether they are located in water abundant or water starved region. Most of the issues are related to improper operation of the system. Serious efforts with utmost concentration ought to be the top-most priority of the Local Authority to emerge out of the severe critical water issue.

Ms. Namrata B Patil and Dr. W N Deulkar has researched on The primary aim of Pimpri Chinchwad Municipal Corporation (PCMC), Pune is to provide water to the consumer for $24 * 7$ hours by framing the legislation on regulation of drinking water through a scheme which is named as $24 * 7$ water supply scheme, hence before provision of continuous water supply, we have considered 'leakages' in the distributaries as it is the most responsible factor for water contamination. For detecting leakages and to provide safe qualities of water, a sample of water from consumer water tap was analyzed for chlorine and turbidity test. Helium gas was used to detect leakages in the water mains. It is seen that, this technique is safe, easy to operate and have accurate results to find leakages in water mains.

Yogendra P Joshi1, M. B. Tadwalkarhas worked on Flow sensor based water meter presents very low cost, reliable, quick water meter system accompanying with existing GSM networks. Paddle wheel flow sensor JT121 measures the water flow accurately with the help of rotating paddles. Monthly water usage can be sent to municipal corporation office within fraction of seconds in the form of text message by using existing GSM network. Such metering system reduces manpower, with higher accuracy and less power consumption. It gives better results than any other metering systems such as mechanical, ultrasonic, electro-magnetic systems. By using this system water consumption can be observed in real time with controlled use of precious water resources. Water resources be managed for future planning. Non-revenue water will be detected and loss can be avoided in distribution system.

\section{Methodology}

Helium Mass Spectrometer (MS) Leak Detection Method This method was first used in Manhattan, New York by the Uranium Enrichment Plant for „Manhattan Project ${ }^{e e}$. This method is used for the first time in India and for the second time in the world. In India it is been used for the project, ,24*7 Water Supply System ${ }^{\text {ce }}$ in sector 21, PCMC. Helium gas is used for leak detection because it is Non-toxic, Inert and

non-condensable, not present in the atmosphere at more than trace amounts, relatively inexpensive, readily passes through leaks due to its small atomic size, Non-flammable, Available in various size cylinders, and Available in purities appropriate for medical usage. This gas belongs to zero group (Noble gases) in periodic table having atomic mass 4.002202

2.1 Procedure for Helium Gas Leak Detection Leakage on the pipe line was finding out by carrying three steps.

1) Helium Injection

2) Pipe \& Cable Detection

3) Leakage Detection

The details of the above steps are given below

1. Helium Injection:

$>$ Initially, a cylinder of Helium gas is fixed to the outlet of the ESR.

$>$ The injecting pressure of the Helium gas was maintained such that $30 \%$ of the Helium gas in the cylinder has to be injected in 30 minutes.

$>$ For this criterion, the pressure was to be maintained at $9.5 \mathrm{~kg} / \mathrm{cm}^{2}$.

$>$ The pressure was checked at an interval of 15 mins.

$>$ A Pressure-meter to measure the pressure of the water in the pipe was attached to the pipe. 


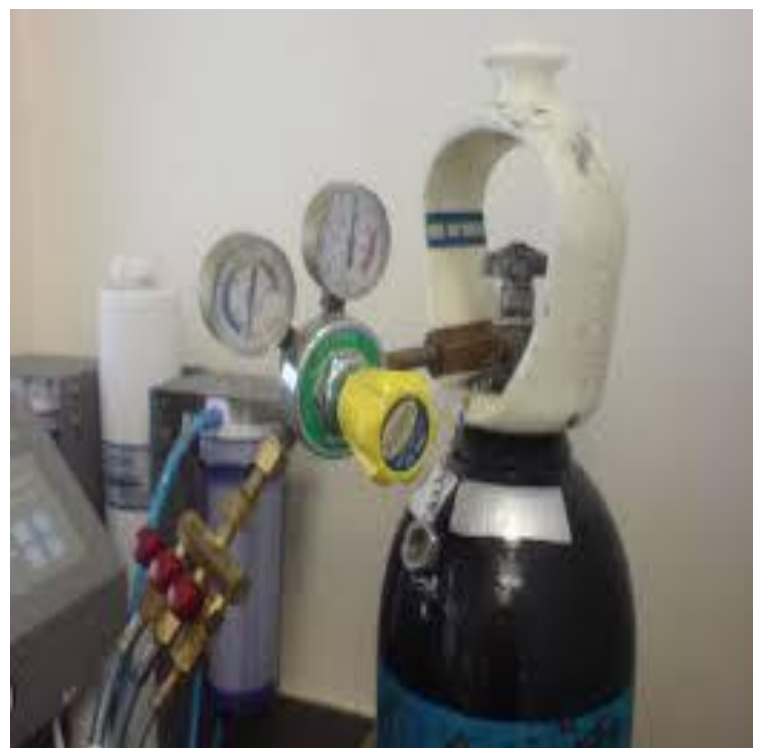

Fig.2.1 Pressure meter with Helium gas cylinder

\section{Pipe \& Cable Detection}

$>$ With the help of Pipe \& Cable Detector, the underground pipes and cables are detected. Fig.2.2.

$>$ The Locator is having the receiver and transmitter; receiver is divided in two parts - Antenna \& Receiver. Fig.2.2.

$>$ The Receiver receives reflected waves from the cables and indicates the location and the depth of cables. After detecting the cable, a hole is drilled at every $2 \mathrm{~m}$. to $3 \mathrm{~m}$. apart from the point where the cable is detected so as to avoid drilling in the cable. The depth of the hole is $40 \mathrm{~cm}$. Fig.2.2.

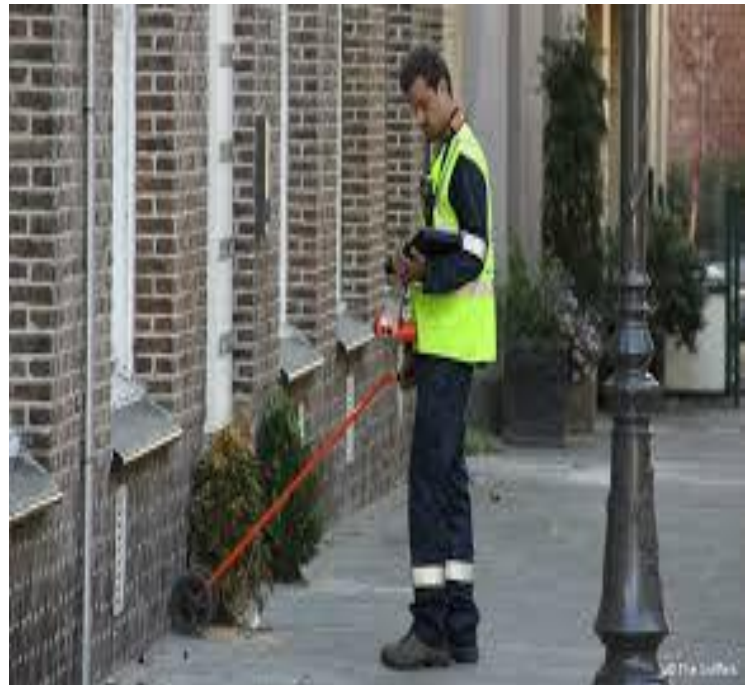

Fig.2.2. Leak detection

\section{Leakage Detection}

A Above the drilled holes, a vacuum pipe is placed that is connected to the Spectrometer Fig.2.3. There is a filter in between the vacuum pipe and spectrometer which filters the moisture and soil particles coming from the vacuum pipe, if any. Only air is carried away further.

$>$ Next to the filter there are two jars containing silica gel (Blue color). A sniffing probe is connected to one of the jars.

$>$ The silica gel filters the moisture if any after filtering and hence protects the spectrometer.

$>$ The filtered air finally enters in the spectrometer. The spectrometer then shows the amount of the Helium gas. The saturated concentration of helium is $3.5 \times 10^{-6} \mathrm{Kg} / \mathrm{cm}^{2}$ in the atmosphere but if the spectrometer reading is exceeding $7 \times 10^{-6} \mathrm{~kg} / \mathrm{cm}^{2}$ then there is a possibility of leakage. At such case, few more holes are drilled along the radius of the detected hole, if the reading is increasing or up to $7 \times 10^{-6} \mathrm{Kg} / \mathrm{cm}^{2}$ then surely there is a leakage.Fig.2.3. 


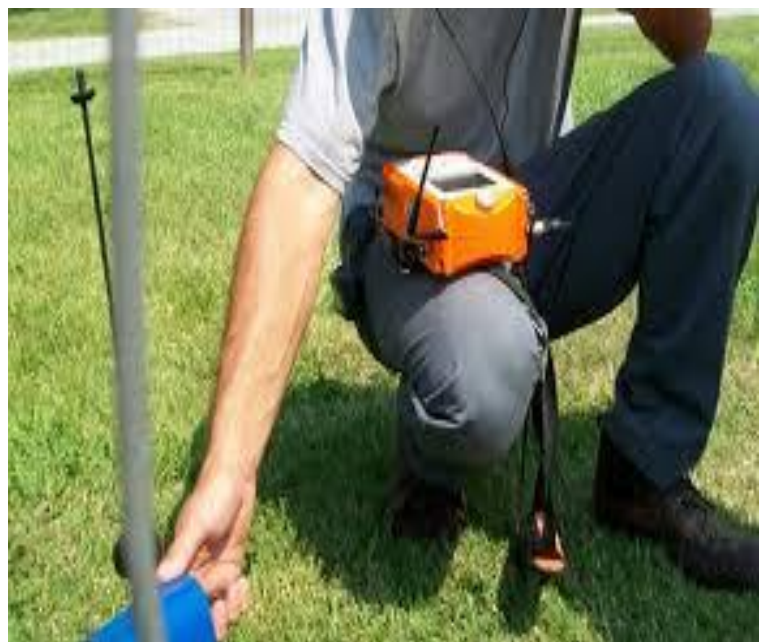

Fig.2.3. Picture during leak detection

\subsection{Leakage Repair Work}

After detecting leakages on pipeline in sector 21, following types of connection repair is done 1 . Ferrule Connection: ferrule is used when at end of pipe leak is found. Following Fig. 2.4shows the ferrule connection.

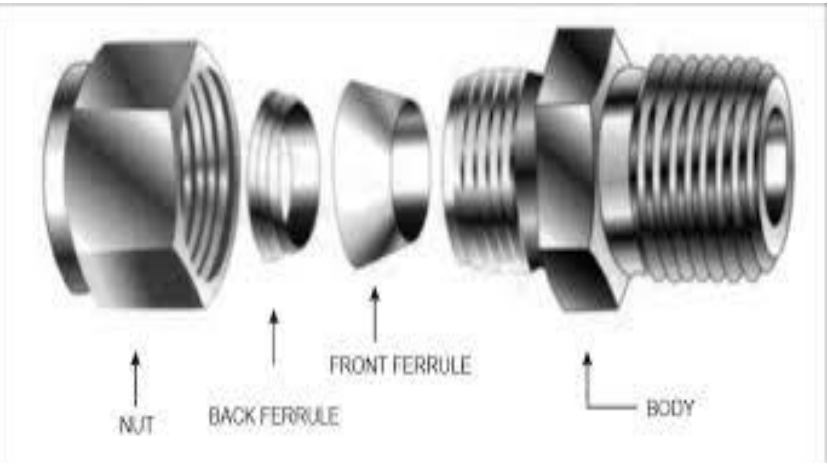

Fig.2.4. Ferrule connection

1. Sluice Valve: A Sluice Valve is often used on larger diameter mains (2" or greater) mainly for industrial and commercial feeds. This works covers or maintenance and renewals of any type of Sluice Valve including, chamber frame and cover rebuilds, repacking glands, is spindles, repairs to bolts and flange plates and full replacement of valves with main work. Figure 2.5 shows the sluice valve repair

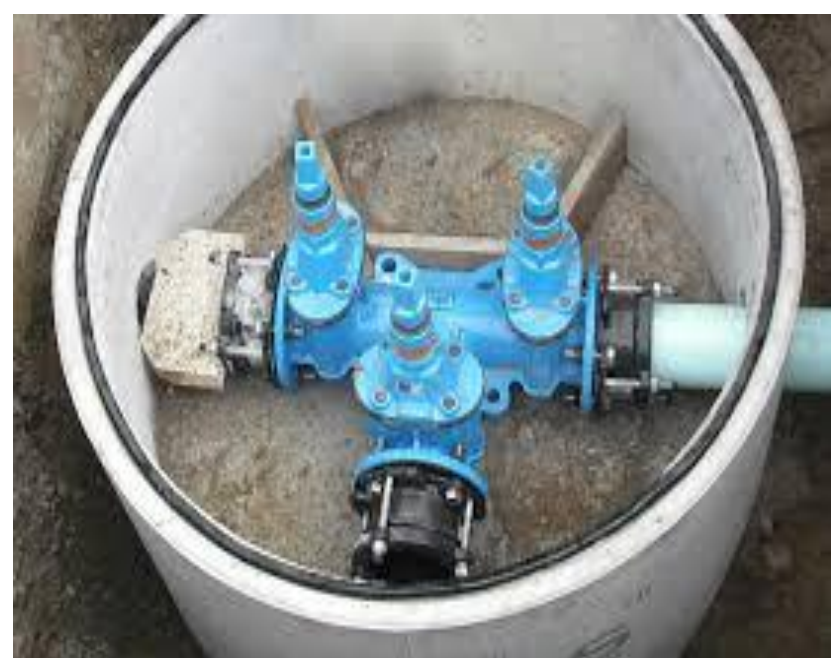

Fig.2.5. Sluice valve repair 


\section{Mains Repair}

This covers all repairs and maintenance of all water mains and supply pipes greater than 1" in diameter. There are many different types of materials that have been used in the installation of water mains from Asbestos Cement, PVC, Medium Density Polyethylene (MDPE), copper, galvanized iron to the more common ductile and cast-iron. With this there are many fittings to adopt and maintain these different materials for use in repairs to water mains, new connections for supplies to properties and general preservations, refer the Fig. 2.6 below.

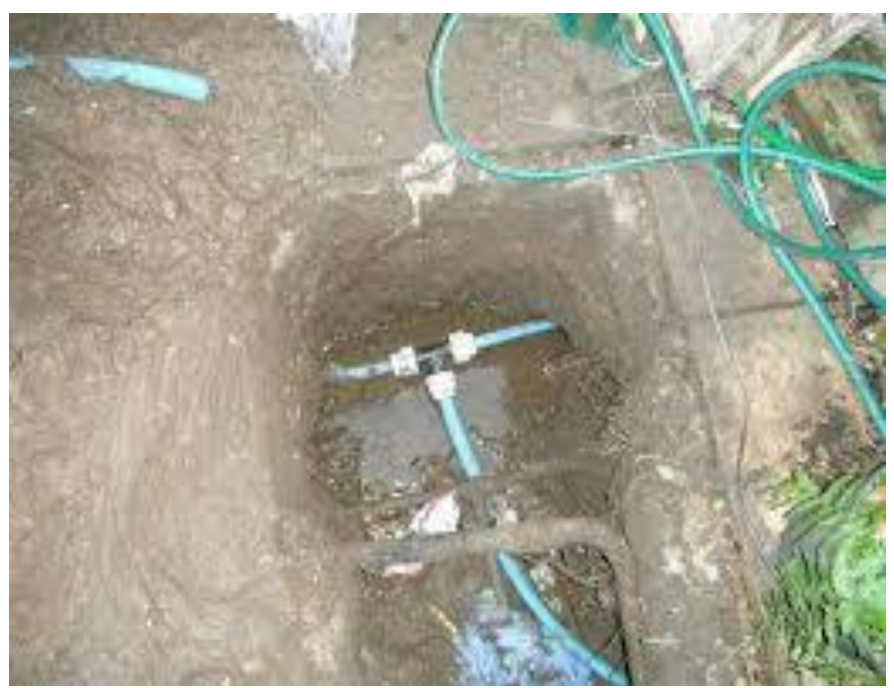

Fig.2.6. Main repaired connections

\section{Conclusion}

The intermittent water supply system is adopted by almost all towns and cities that comprises severe deficiencies which lead to poor water quality and pressures, inadequate quantity, discomfort and inconveniences, contamination etc. The water provided by PCMC to all people of sector 21 is of standard quality and passes the safe permissible.This overcomes existing systems in terms of cost and manpower required. Minimized cost of the whole system will support to use as economical and logical metering system. Monthly billing cycle can be maintained to limit the use of precious natural resource water.

\section{References}

[1]. Dr. Sanjay and V. Dahasahasra, "A model for transforming an intermittent into a $24 \times 7$ water supply system", (August 2007).

[2]. Sandul Yasobant \& Kranti Suresh Vora, "A situational analysis of $24 \times 7$ primary health Centre from Gujarat", (IJSRD Vol 1, issue 2, 2013).

[3]. Namrata Patil \& Dr. V. N. Deulkar, "Quality management of water supplies under $24 x 7$ schemes, at sector no.21,PCMC, Pune", (IJERA, vol 3, issue 4, Jul-Aug 2013).

[4]. Priya Sangameshwaram, Clifton D. Rozario $24 \times 7$, 'Privatization and Water Reform', ( th $^{\text {th }}$ April, 2008).

[5]. Karnataka Urban Water Sector Improvement Project, "Innovations Under Development, Karnataka Three Towns Pilot 24x7 Water Supply", (2013 issue 12).

[6]. Yogendra P. Joshi \& M. B. Tadwalkar, "Implementation of GSM Based Water Meter A Step towards Automation in Billing System" (Jul-Aug 2014).

[7]. Case study of Nagpur $24 \times 7$ water supply system.

[8]. Case study of Badlapur $24 \times 7$ water supply system. 